\title{
Reflex anoxic seizures ('white breath-holding'): nonepileptic vagal attacks
}

\author{
J. B. P. STEPHENSON \\ From the Fraser of Allander Unit, Royal Hospital for Sick Children, Glasgow
}

SUMMARY From clinical history 58 children were diagnosed as having reflex anoxic seizures secondary to provoked cardioinhibition (also known as white breath-holding attacks). Before referral, these seizures were commonly misdiagnosed as epileptic either because the provocation was ignored, not recognised, or was a febrile illness, or because there was no crying, no obvious breath-holding, little cyanosis, and often no pallor to suggest syncope and cerebral ischaemia. The duration of cardiac asystole after ocular compression was measured in these children and in 60 additional children with other paroxysmal disorders. In $45(78 \%)$ of the 58 with reflex anoxic seizures asystole was 2 seconds or over, and in $32(55 \%)$ it was 4 seconds or greater, an abnormal response. Review of the literature supports the concept that these seizures result from vagal-mediated reflex cardiac arrest which can if necessary be prevented by atropine. The simple name 'vagal attack' is proposed. Ocular compression under EEG and ECG control supports the clinical diagnosis if asystole and/or an anoxic seizure is induced; the procedure described is safe and should be routine in seizure or syncope evaluation, when a meticulous history still leaves room for doubt.

The honest paediatrician must confess that the terms seizure, fit, or convulsion conjure up the spectre of epilepsy, if not present yet to come. Because a single seizure, even if shrugged off as simply a benign convulsion, is thought of as epileptic in mechanism (that is, involving the excessive hypersynchronous discharge of a population of cerebral neurons), it is no surprise that the child with recurrent seizures unprovoked by fever soon acquires a diagnosis of epilepsy. Despite Gastaut's cogent exhortations (Gastaut and Gastaut, 1958; Gastaut, 1974), the question 'were the seizures anoxic rather than epileptic?' is still seldom asked. Breath-holding (Gauk et al., 1963; Lombroso and Lerman, 1967,) syncope (Sharpey-Schafer, 1956; Gastaut, 1974), infantile syncope (Sheldon, 1952; Bower, 1974), and cerebral ischaemia from cardiac arrhythmias (Scott et al., 1976; Radford et al., 1977) are all well recognised, so why should this be so? I think an explanation lies in the lack of a universal descriptive name to label the attacks which form the subject of this paper. Because their languages had no word for it, continental European paediatric neurologists had difficulty in understanding what Robson (1970) meant by the term 'shuffler' until he performed a mime on stage (Robson, 1977). A similar difficulty obscures the recognition of those reflex anoxic

Received 11 November 1977 seizures which appear to depend on vagal-mediated cardiac arrest after minor provocation.

In a typical case an unsteady toddler on his own trips and falls. His mother hears the bump but no succeeding cry and hurries to him. She finds her child lying deathly still with eyes fixed upwards, lips dusky. As she lifts him, he abruptly stiffens into rigid extension with jaw clenched and hands fisted, gives a few jerks, and after what seems an age (but in fact is less than half a minute) relaxes limply with an absent far-away look. Then he opens his eyes, at once recognises his mother, cries a little, and drifts off to sleep, his face distinctly pale.

These alarming episodes have been variously called breath-holding spells with vagotonia (Bridge et al., 1943), type II transient hypoxic crises (Maulsby and Kellaway, 1964), breath-holding spells of pallid type, or pallid infantile syncope (Lombroso and Lerman, 1967), reflex anoxic cerebral seizures with 'white' syncope (Gastaut, 1968), or colloquially, white breath-holding attacks. Such descriptions apart from being over-long are unhelpful or even misleading, because in an attack there may be no obvious breath-holding and no pallor to suggest syncope (Lombroso and Lerman, 1967). It is the purpose of this present paper to draw attention to these distinctive 'white' reflex anoxic seizures without an established name, to support the routine use of ocular compression under electroencephalographic 
(EEG) and electrocardiographic (ECG) control as an aid to diagnosis, and to suggest the term vagal attack as short, meaningful, and clinically useful.

\section{Patients and methods}

During the 5-year period 1972-1977, 118 children had ocular compression and an EEG as an aid to the diagnosis of reflex anoxic seizures. Of these, $111 \mathrm{had}$ ocular compression while the EEG and ECG were recorded simultaneously, and the remaining 7 children had ocular compression with cardiac monitoring after the EEG examination. Clinical histories were available for all the 118 children; additional information was obtained in 29 of these, who attended a paediatric neurology clinic and were the subject of a personal study - all 7 who had ocular compression separate from EEG were in this latter group. There were 50 boys and 68 girls in the series, aged from 10 months to 14 years at the time of testing, with the exception of one 3-month-old baby. The median age at test was just less than 4 years.

Ocular compression (modified from Lombroso and Lerman, 1967) was carried out for a maximum of 10 seconds by applying strong pressure with the thumbs, just below the supraorbital ridges, over the closed eyelids of the child who was lying supine (Figs. 1, 2). EEG electrodes were attached in standard manner (international 10-20 system), and the ECG, from a plate electrode on the left leg coupled
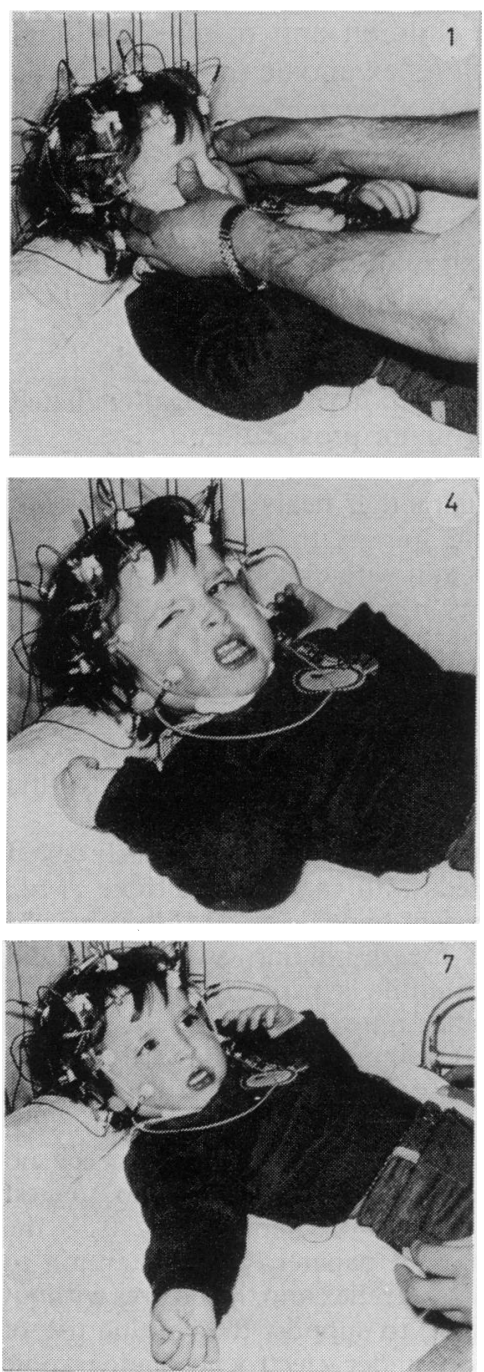
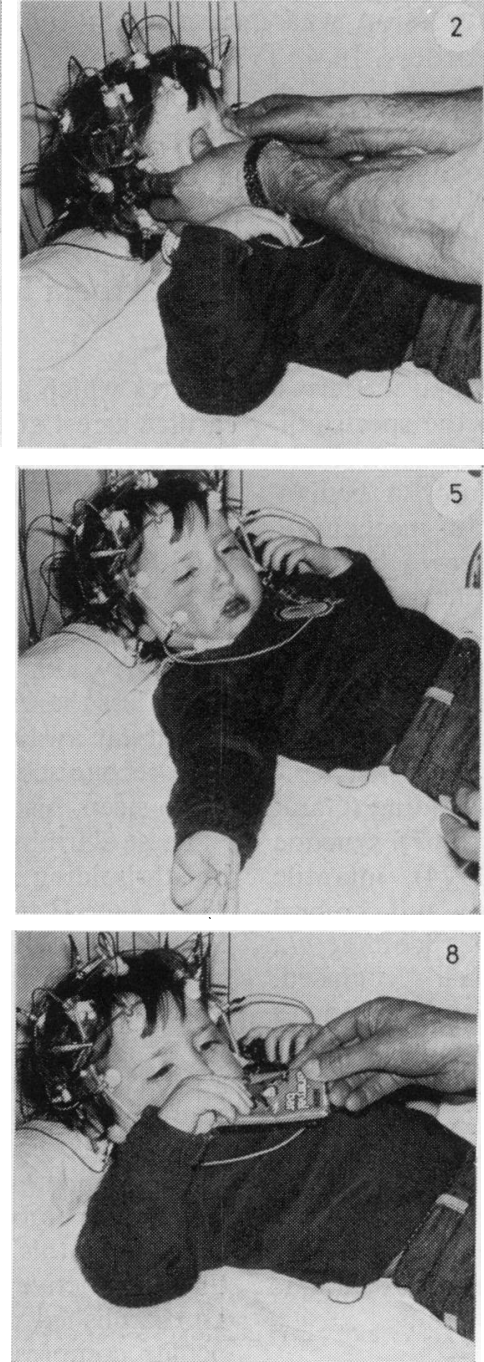
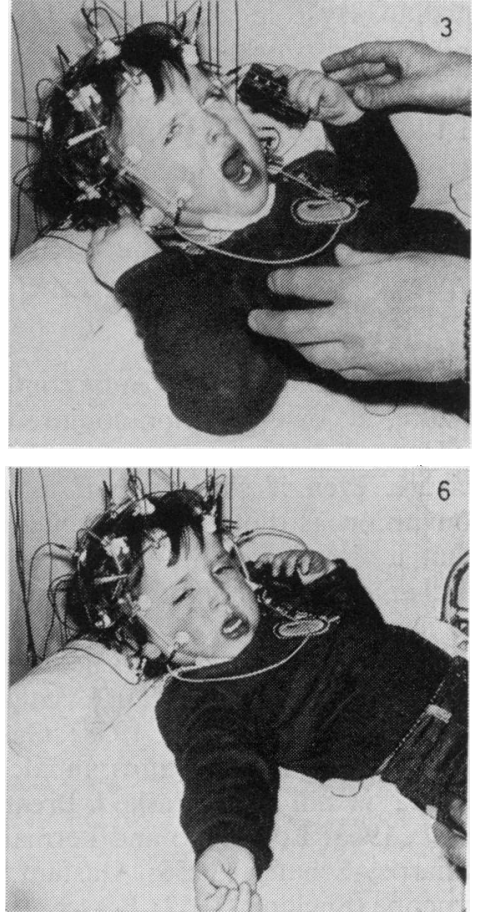

Figs. 1-8 Ocular compression inducing a 'white' reflex anoxic seizure in a child prone to such attacks. Note the ocular revulsion in Fig. 3, tonic phase (during EEG flattening) in Fig. 4, atonic absence in Figs. 5 and 6, and very rapid recovery. Cardiac asystole lasted 11 seconds but there was only minimal cyanosis and no pallor (confirmed by colour photographs). 
to scalp electrode $\mathrm{Fz}$ was recorded simultaneously as a single channel on the same paper as the EEG (Fig. 9). Throughout the procedure the EEG technician tapped out the systolic rhythm with a pencil to give an audible signal to the paediatrician (the author in over $85 \%$ of cases) who was performing the ocular compression. Resuscitation equipment was available in the EEG room but in practice was never required and the child was left undisturbed and unstimulated however long the induced asystole (maximum observed arrest 23 seconds).

From the clinical description the children were classified into four groups (Table 1). (1) Reflex anoxic seizures of the 'white' or pallid type, as found in infancy and early childhood. The basis for inclusion in this group was that the child on clinical grounds seemed to fit the description given by Lombroso and Lerman (1967, p. 265) of so-called pallid breath-holding spells (see also Discussion). Typically, a rather minor unpleasant stimulus was followed within seconds by loss of consciousness and posture, without prominent crying or striking cyanosis. In the majority a tonic seizure (sometimes with clonic component) interrupted this atonic absence. Pallor, during or afterwards, was usual but

Table 1 Ocular compression study 1972-1977

\begin{tabular}{lcccc}
\hline & \multicolumn{4}{c}{ Asystole duration $(s)$} \\
\cline { 2 - 5 } Group diagnosis & $<2$ & 2 or more & 4 or more & Total \\
\hline $\begin{array}{l}\text { 1 Reflex anoxic seizures } \\
\text { (white) }\end{array}$ & 13 & 13 & 32 & 58 \\
$\begin{array}{l}\text { Syncope, reflex and } \\
\text { spontaneous }\end{array}$ & 15 & 5 & 28 \\
3 Blue breath-holding & 7 & 3 & 1 & 11 \\
4 Miscellaneous and uncertain & 15 & 5 & 1 & 21 \\
Total & 50 & 29 & 39 & 118 \\
\hline$\chi^{2}$ (group 1 versus group 2 vs. groups 3 and 4 combined) $=$ \\
26.2 , df $2, \mathrm{P}<0.001$.
\end{tabular}

not universal. There were 58 children in this group all less than 7 years at age of onset ( 7 of them were over 7 years at the time of testing).

(2) Syncope, spontaneous and reflex (Gastaut and Fischer-Williams, 1957; Gastaut, 1974). There were 28 cases in this group all aged 7 years or over at onset (with 3 exceptions, a child of 4 years who had simple syncope reflexly precipitated by abdominal pain and 2 others who had simple syncope without known cause at 3 years and 6 years). The children in this group were generally regarded as having simple faints of vasovagal type, the common conception of syncope, with provocations such as a hot environment, erect posture, the sight of blood, and so forth (Engel, 1962).

(3) Blue (cyanotic) breath-holding attacks (Lombroso and Lerman, 1967), 11 cases. In this well-known situation, the child if annoyed or hurt, cried, held his breath in prolonged expiration, became deeply cyanosed, and was then limp (or occasionally stiff); recovery was rapid with renewed respirations.

(4) Miscellaneous and uncertain, including possible white or blue breath-holding, epilepsy, and undifferentiated or unexplained attacks of unconsciousness, 21 cases.

\section{Results}

The effect of ocular compression on the duration of induced asystole differed significantly between these four groups as shown in Table 1. More than $55 \%$ of group 1, those with 'white' reflex anoxic seizures, had an abnormal response (Lombroso and Lerman, 1967) with 4 seconds or more asystole, compared with $18 \%$ of those with classical syncope, and only $6 \%$ of the combined blue breath-holding and miscellaneous groups including those with epilepsy $\left(\chi^{2}=26 \cdot 2\right.$, df $\left.2, P<0.001\right)$. These differences were not significantly influenced by age or sex.

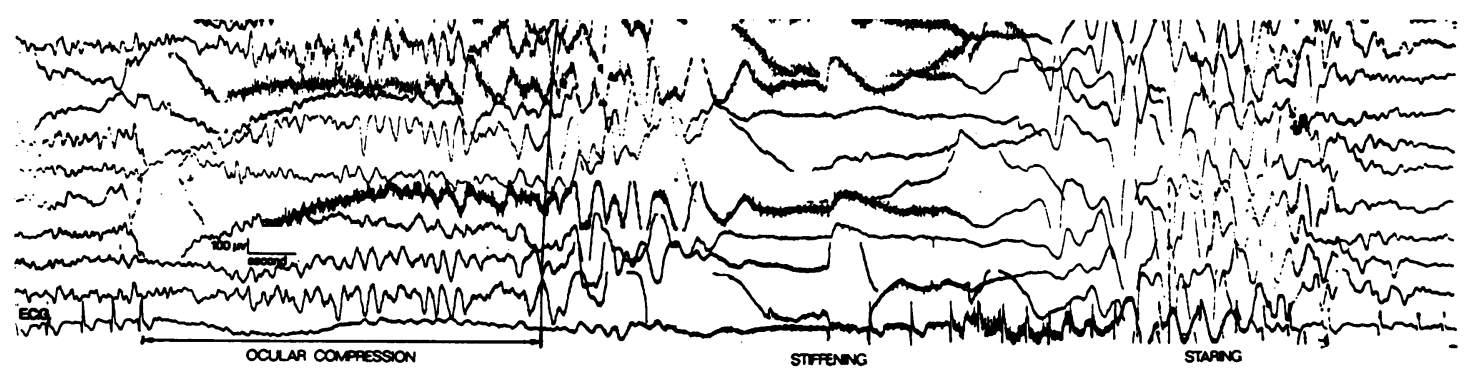

Fig. 9 Simultaneous EEG and ECG during and after ocular compression in a child with reflex anoxic seizures. Asystole lasted for 13 seconds, with flattening of the EEG for 7 seconds during the tonic seizure. The heart restarted 4 seconds before the high voltage slow activity which accompanied a blank stare (anoxic absence). 
Paediatricians who referred more children for ocular compression had a higher proportion of abnormal asystoles among their patients, although the trend was not statistically significant.

Parents' descriptions revealed that the 'white' reflex anoxic seizures had certain characteristic precipitating factors (Table 2), including fever in 8 cases $(14 \%)$, but it was notable that a history of a provoking stimulus could not be established for every anoxic seizure in every child.

Of the personal series of 29 cases of 'white' reflex anoxic seizures seen for neurological investigation, $21(72 \%)$ were referred with a diagnosis of epilepsy or convulsions (Table 3). In this series 19 of the children had tonic seizures (with or without clonic jerks), and 10 atonic seizures without convulsion. Of the total group of 58 children with 'white' reflex anoxic seizures, $12(21 \%)$ had one or more antiepileptic drug prescribed, usually by paediatricians. No genuine spikes consistent with epilepsy were seen in the EEG of any of these children (Table 4).

Table 2 Stimulus to reflex anoxic seizures (white)

$\begin{array}{ll}\text { Predisposing: } & \begin{array}{l}\text { clumsy legs: trips easily } \\ \text { anaemia } \\ \text { behaviour disorder }\end{array} \\ \text { Provocations: } & \begin{array}{l}\text { pain (especially surprising pain, bumps to head) } \\ \text { emotion (surprise, fear, annoyance, frustration, } \\ \text { excitement) } \\ \text { crying } \\ \text { fever (8/58: } 14 \%)\end{array}\end{array}$

Reason not always discovered: often no witnesses

Table 3 Referral diagnosis in reflex anoxic seizures (29 personal cases)

Epilepsy (grand mal, petit mal, minor, mild, previous febrile convulsion, post-traumatic)

Convulsions (no cause, after pain or bumps, febrile)

Loss of consciousness (unexplained, with incontinence, faints, or fits)

Breath-holding (uncertain, not convinced, dangerous?)

Head injury

Frequent falling

Table 4 Reflex anoxic seizures treated as epilepsy (ocular compression study)

\begin{tabular}{lll}
\hline & $\begin{array}{l}\text { Total number of } \\
\text { children }\end{array}$ & $\begin{array}{l}\text { Anti-epileptic drugs } \\
\text { given }\end{array}$ \\
\hline $\begin{array}{l}\text { Reflex anoxic seizures } \\
\text { (white) }\end{array}$ & 58 & $12^{*}(21 \%)$ \\
Other & 60 & 0 \\
\hline
\end{tabular}

* None had genuine EEG spike abnormality; 1-3 drugs prescribed per child, mean 1.4; paediatrician began treatment in 8 children.
Table 5 Parents' descriptions: reflex anoxic seizures

Prodrome: runs slowly, legs wobbly, 'dozey', tries to cry, groans: 'like wind coming out of a balloon'

Posture: head rolls, neck 'broken', soft, limp, keels over

Eyes:

Jaw: roll, up, back, 'pop out of head' clenched, teeth 'gritted'

Tone change: stiffens, back arched like a cat; arms twisted, sticking out, fists clenched

Jerks: odd, slow, slight

Continence: may wet

Colour: ashen under eyes, blue or purple lips, yellow patches through the blue; whitey, grey, waxy, no blood in the skin, like a corpse-no life at all; no colour change noticed

Recovery: wants to sleep or be nursed, sleeps, or gets up and runs away

The parents' descriptions of the reflex anoxic seizures themselves had certain characteristics in common (Table 5), and in any particular child the form of the seizure was stereotyped although of varying severity. If an anoxic seizure was induced by ocular compression (Figs. 1-8), then the parent present would recognise it as typical but usually added that the 'natural' attacks looked worse.

\section{Discussion}

The 58 children in group 1 (Table 1) were clinically regarded as having reflex anoxic seizures from vagal-mediated cardiac inhibition on the basis of the history. The attacks resembled the so-called pallid breath-holding spells or pallid infantile syncope as described by Lombroso and Lerman (1967), but as pointed out by these authors breathholding was not a conspicuous feature and pallor was often not evident. This class of seizure was first clearly delineated by Maulsby and Kellaway (1964) as their type II hypoxic crisis of childhood, which they contrasted with the type I crisis or breathholding spell: 'The type II hypoxic crises were precipitated exclusively by unexpected painful stimuli such as a blow to the head. The child, without crying and without any apparent conscious acknowledgement of the insult, suddenly falls limply unconscious. He may then quickly regain consciousness or he may have an opisthotonic and clonic seizure followed by another atonic phase before consciousness is regained. Usually there is no cyanosis. Although it is often not obvious to the observer, the child usually does not breathe during the initial phase of the attack, the respiration being arrested in the expiratory position'. Lombroso and Lerman (1967) gave a similar definition of this type of seizure, again comparing it with the more common cyanotic breath-holding spell: 'a second welldefined group ... lost consciousness following the stimulus much more quickly than the first group, with a minimum of crying and usually more often 
without cyanosis. Pallor was often described in this group, and convulsive phenomena were seen as the attacks terminated'.

Lombroso and Lerman (1967) were the first to show that children with pallid breath-holding spells were distinctive (and different from those suffering from blue breath-holding spells) in being abnormally sensitive to the heart-slowing effect of ocular compression. The present study confirms this: more than half of those with 'white' reflex anoxic seizures had a duration of induced asystole of 4 seconds or more, an effect never seen in the control group of Lombroso and Lerman (1967). The group with classical syncope was intermediate in this respect (cf. Gastaut and Fischer-Williams, 1967), while in the blue breath-holding and miscellaneous groups abnormal asystole was only observed twice. One such child was classified as blue breath-holding because of the depth of cyanosis reported, but the very rapid evolution of the tonic seizure after the provocation was compatible with cardioinhibition as the underlying mechanism. The other child with abnormal asystole was relegated to the 'miscellaneous' group because of insufficient history (the episodes occurred in a school bus), but was in fact the sister of one of those in group 1.

The assertion that the 'white' reflex anoxic seizures here described result from vagal-mediated cardiac arrest is based on five related pieces of evidence: (1) They closely resemble the experimental seizures induced when ocular compression leads to cardiac asystole either in the sitting (Gastaut and Gastaut, 1958; Gastaut et al., 1961; Gastaut, 1974) or in the supine position (Lombroso and Lerman, 1967), which in turn resemble the seizures caused by acute uncomplicated interruption of the cerebral circulation (Rossen et al., 1943).

(2) If ocular compression does induce an anoxic seizure in a particular child then the parent witnessing will recognise it as identical to the child's regular attacks (Gastaut and Gastaut, 1958; Lombroso and Lerman, 1967; present study).

(3) Even if an anoxic seizure is not so induced, ocular compression is likely to trigger asystole of abnormal (4 seconds) duration (Lombroso and Lerman, 1967; present study). Although 6 out of 83 (7\%) of the age-matched control group of Lombroso and Lerman (1967) developed asystole of 2 seconds or more, in none did asystole extend to 4 seconds.

(4) On the few occasions when it has been possible to witness 'natural' attacks induced by emotion or noxious stimuli other than the artificial procedure of ocular compression, asystole or extreme bradycardia has been observed at the onset (Bridge et al., 1943; Bridge, 1949; Maulsby and Kellaway, 1964); one such fortuitious episode with 24 seconds asystole in a $2 \frac{1}{2}$-year-old girl is illustrated in figure 10 of Lombroso and Lerman (1967).

(5) Atropine can prevent both the naturally occurring seizures and the abnormal response to ocular compression (Maulsby and Kellaway, 1964; Lombroso and Lerman, 1967).

That reversible cardiac arrest can cause episodic unconsciousness or seizures has been known since early in the last century (Adams, 1827; Stokes, 1846). Since then the term Stokes-Adams disease has been confined to patients with heart block (and thus heart disease), in whom the atria continue to beat during the attacks of ventricular standstill (Parkinson et al., 1941). These authors, concentrating on the ECG appearances, contrasted the situation in syncope and illustrated asystole exceeding 4 seconds with sinus arrest resulting from pressure on the right eyeball in a 4-year-old boy (p. 172, figure 2). So-called intermittent StokesAdams syndrome with transient complete heart block has been described in adults with abnormal oesophageal structure (Weiss and Ferris, 1934) or function (Havland and Frithz, 1976). The StokesAdams definition should not be stretched further to include reflex atrial and ventricular asystole in those with presumed normal hearts, but with exaggerated vagal reflexes (Schwartz and Schwartz, 1966).

The oculo-cardiac reflex has been of the utmost value in the demonstration of such excessive vagal reactions. It was discovered independently by Aschner (1908) and Dagnini (1908) and is a brainstem reflex with the afferent limb the ophthalmic division of the fifth nerve and the efferent path the vagus. There is some evidence that compressing the right eye leads to cardiac slowing and the left to cardiac conduction defects (Levine, 1915) but in practice both eyes are pressed simultaneously just below the supraorbital ridges (Bellett, 1971). Most authors who have used the technique in the study of seizure disorders have used digital compression, but Lombroso and Lerman (1967) used a specially constructed ocular tonometer to apply a pressure of 100 to $200 \mathrm{~g}$ - they found the manual method equally effective though less precise. Those who have investigated the oculo-cardiac reflex in ophthalmic surgery have directly manipulated the extraocular muscles (ApIvor and Ravi, 1976) and such evidence as there is does not suggest that varying the tension applied alters the ECG effect (K.M.S. Dewar, personal communication, 1977).

In the study of reflex anoxic seizures ocular compression has been performed on a very large number of individuals without reported complication (Bridge et al., 1943; Gastaut and Gastaut, 1957, 1958; Gastaut et al., 1961; Fildisevski, 1961; Maulsby and 
Kellaway, 1964; Lombroso and Lerman, 1967; Gastaut, 1968, 1974). Maulsby and Kellaway alone had, at the time of publication, used the test more than a thousand times. The longest cardiac arrest induced has been 32 seconds (Gastaut et al., 1961); asystoles of 20 seconds or more have not been uncommon, always reversing spontaneously. Although children have died during strabismus surgery with the oculo-cardiac reflex implicated (Sorensen and Gilmore, 1956; Stephenson, 1974), I can find no documentation of a fatality in an awake child. Landman and Ehrenfeld (1952) reported 'nearly fatal' ventricular fibrillation' after ocular compression for supraventricular tachycardia, but there was by presumption heart disease, and inspection of their illustrations suggests not fibrillation but ventricular tachycardia at worst. One unsubstantiated ancedotal warning is to be found in the literature: ' $I$ am told that experts in the techniques of unarmed combat recognise that severe pressure on the eyes can cause syncope, and if violent enough, death' (Mallinson and Coombes, 1960). It therefore seems a wise precaution (which we take, like Lombroso and Lerman) to have resuscitation equipment available in the EEG room, even though the physician who performs the ocular compression will never need to use it.

Direct traumatic ocular complications have not been described in children after the test; high myopia is mentioned as a contraindication by Lombroso and Lerman, but this seems only to apply to the elderly and certainly not to the young child. From a study of the literature and from my own experience (including over 50 ocular compression tests monthly since this study was completed) I would recommend that ocular compression under EEG and ECG control, as described under Patients and methods (see also Figs. 1-8, 9), is a safe and valuable technique which should form part of the routine EEG examination of any child with unexplained seizures. I would go so far as to suggest that in this clinical situation it is of little value to refer a child to an EEG department unable to provide this investigation.

As all authors who have used ocular compression in this field have strongly emphasised, it is of the utmost value to a child to be able to positively support the diagnosis of reflex anoxic seizures as opposed to epilepsy or the possibility of it. The relief of the parents when such a diagnosis is made and the improvement in the child when sedative antiepileptic drugs are discontinued is often very striking (Lombroso and Lerman, 1967). The number of children referred as epileptic, and the proportion treated by paediatricians with antiepileptic drugs in the present series testify to the continuing difficulties of diagnosis. Certain clinical factors tend to confuse the clinician (Table 6), in particular a misinterpretation of the provoking stimulus. Several published papers refer to water-immersion epilepsy (Allen, 1945; Mofenson et al., 1965; Keipert, 1969, 1972; Pearn, 1977) where the reported clinical features actually suggest reflex anoxic seizures. A major textbook of paediatric neurology (Swaiman and Wright, 1975a) quotes Forster (1972) in evidence that pain may precipitate a temporal lobe seizure, but in fact the latter author gives no EEG evidence of this, and Gastaut and Tassinari (1966), in their comprehensive review of triggered epilepsy, could find no EEG proof of pain-induced epilepsy.

Although a painful surprise is the best known precipitant of a 'white' reflex anoxic seizure, in the present series, as in that of Lombroso and Lerman (1967), the provoking stimulus was by no means confined to unexpected pain (Table 2). Further, in 8 of the 58 children seizures of apparently indentical form were precipitated during febrile illnesses, and one child had as many as twenty 'febrile convulsions' of this type. The possibility that some febrile convulsions might be vagal-mediated reflex anoxic seizures (J. B. P. Stephenson, in preparation) has been ignored by most authors (Lennox-Buchthal, 1973; Brazier and Coceani, 1976) although 20 years ago McGreal $(1956,1957)$ pointed out the similarity of certain tonic and atonic febrile convulsions (about $8 \%$ ) to breath-holding spells, and Gastaut and Gastaut $(1957,1958)$ showed that anoxic seizures could be induced in many such children by ocular compression. Actually, Lennox-Buchthal (1976), quoting examples from Miller et al. (1960), admits that 'the child with febrile convulsions (an estimated 5-10\%) may have an occasional afebrile convulsion, usually one or two, and often under certain conditions such as after $a$ slight blow to the head or during violent struggling or crying' (my italics). Emotional factors (Table 2) are powerful stimuli to reflex anoxic seizures, but were not always recognised in the present study and were sometimes assumed to be a trigger for epileptic fits, despite there being no EEG evidence of this in the literature (Gastaut and Tassinari, 1966). Stress convulsions (Friis and Lund, 1974) might be invoked as an exception; however, the older children and adults reported had no other evidence of epilepsy but did have a strong familial disposition to febrile convulsion.

Table 6 Confusing factors in reflex anoxic seizure diagnosis

Provocation not witnessed, recognised, or remembered Fall regarded as ictal, or as cause of head (brain) injury

Pain, emotion. or fever assumed to be provocation of epileptic fit Lack of fever translated as 'unprovoked'

Lack of pallor thought to exclude cerebral ischaemia 
It is an important practical point that in this series provocations were not always evident or witnessed by the parent before every attack. When the provocation is not recognised or remembered, it is all too easy to label the seizure epileptic when one means epileptiform (Temkin, 1971). No one has described this confusion better than Gastaut (1974), '. . . lipothymia is confused with either a petit mal absence or a temporal lobe seizure . . . a convulsive syncope is mistaken for a convulsive epileptic seizure generalised from the onset. Such a confusion is possible in patients of all ages but is particularly common in infants whose unusually frequent reflex syncopes are systematically called "convulsions" and considered to be epileptic. This deplorable error arises from the custom of calling any loss of consciousness in infancy with ocular revulsion a "convulsion" and of considering any childhood "convulsion" to be epileptic'. Table 6 lists the more important confusing factors brought out by the present study.

It is important for the paediatrician to be keenly aware that reflex anoxic seizures exist and are common (approximately $8 / 1000$ preschool children from the prospective study of Lombroso and Lerman, 1967) but may require meticulous history taking and ocular compression studies for diagnosis. Correction of anaemia possibly prevents attacks (Holowach and Thurston, 1963), but diagnosis alone is often therapeutic. Drug treatment in the form of atropine $0.01 \mathrm{mg} / \mathrm{kg}$ per day (Swaiman and Wright, 1975b) may be required when attacks are very frequent, occur in early infancy, and on occasion as a kindness to anxious baby-sitters. Whether these children are later at greater risk from death by vagal inhibition (Simpson, 1949) is not known, but in any event the recommended term 'vagal attack' in the medical history should alert physicians to the need for atropine in risky circumstances. Meanwhile, further research is needed to determine if there is any relation between reflex anoxic seizures and 'near miss' sudden infant deaths now that vagal bradycardia has been postulated as a mechanism for some of the latter (Schwartz, 1976; Guilleminault et al., 1976, Keeton et al., 1977). The present guess is that the mechanisms are very different, with the suspicion of impaired protective sympathetic drive in the 'near-miss' infants up to 3 months of age (Schwartz, 1976) and excessive but always reversible vagal discharges in the older children with reflex anoxic seizures.

I am grateful to many colleagues for the opportunity to study their patients (in particular Dr K. L.' Dodd who had the care of the boy in Figs. 1-8) and for helpful discussions. I thank Miss G. M. Block, Chief
Technician, EEG Department, for enthusiastic cooperation, and the Department of Medical Illustration, R.H.S.C. for the pictures. This paper was presented in part at the Scottish Paediatric Society summer meeting, Inverness, 1977.

\section{References}

Adams, R. (1827). Cases of diseases of the heart accompanied with pathological observations. Dublin Hospital Reports, 4, 353-453.

Allen, I. M. (1945). Observations on cases of reflex epilepsy. New Zealand Medical Journal, 44, 135-142.

ApIvor, D., and Ravi, P. K. (1976). Ketamine and the oculocardiac reflex. Anaesthesia, 31, 18-22.

Aschner, B. (1908). Ueber einen bisher noch nicht beschriebenen Reflex vom Auge auf Kreislauf und Atmung. Verschwinden des Radialpulses bei Druck auf das Auge. Wiener Klinische Wochenschrift, 21, 1529-1530.

Bellett, S. (1971). Clinical Disorders of the Heart Beat, 3rd ed., p. 1167. Lea and Febiger, Philadelphia.

Bower, B. D. (1974). Fits, faints, and "funny turns" in young children. British Journal of Hospital Medicine, 12, 527-534.

Brazier, M. A. B., and Coceani, F. (1976). (Editors.) Brain Dysfunction in Infantile Febrile Convulsions. Raven Press, New York.

Bridge, E. M. (1949). Epilepsy and Convulsive Disorders in Children, p. 114. McGraw-Hill, New York.

Bridge, E. M., Livingston, S., and Tietze, C. (1943). Breathholding spells. Journal of Pediatrics, 23, 539-561.

Dagnini, G. (1908). Interno ad un riflesso provocato in alcuni emiplegici collo stimolo della cornea e colla pressione sul bulbo oculare. Bollettino della Scienze Mediche, 8, 380.

Engel, G. L. (1962). Fainting, 2nd ed. Thomas, Springfield, Illinois.

Fildisevski, P. (1961). Diagnostic value of oculo-cardiac reflex in differentiation of syncope and epileptic manifestations. Cerebral Anoxia and the Electroencephalogram, pp. 554-560. Ed. by H. Gastaut and J. S. Mayer. Thomas, Springfield, Illinois.

Forster, F. M. (1972). The classification and conditioning treatment of the reflex epilepsies. International Journal of Neurology, 9, 73-86.

Friis, M. L., and Lund, M. (1974). Stress convulsions. Archives of Neurology, 31, 155-159.

Gastaut, H. (1968). A physiopathogenic study of reflex anoxic cerebral seizures in children (syncopes, sobbing, spasms and breath-holding spells). Clinical Electroencephalography of Children, $\mathrm{pp}$. 257-274. Ed. by P. Kellaway and I. Petersén. Grune and Statton, New York.

Gastaut, H. (1974). Syncopes: generalised anoxic cerebral seizures. Handbook of Clinical Neurology, Vol. 15, pp. 815-835. Ed. by P. J. Vinken and G. W. Bruyn. NorthHolland, Amsterdam.

Gastaut, H., and Fischer-Williams, M. (1957). Electroencephalographic study of syncope. Lancet, 2, 1018-1025.

Gastaut, H., and Gastaut, Y. (1957). Syncopes et convulsions. A propos de la nature syncopale de certains spasmes du sanglot et de certaines convulsions essentielles hyperthermiques ou à froid. Revue Neurologique, 96, 158-163.

Gastaut, H., and Gastaut, Y. (1958). Electroencephalographic and clinical study of anoxic convulsions in children. Electroencephalography and Clinical Neurophysiology, 10, 607-620.

Gastaut, H., and Tassinari, C. A. (1966). Triggering mechanisms in epilepsy: the electro-clinical point of view. Epilepsia, 7, 85-138. 
Gastaut, H., Fischer-Williams, M., Gibson, W., and El Ouahchi, S. (1961). Clinico-electroencephalographic study of reflex vaso-vagal syncope provoked by ocular compression. Cerebral Anoxia and the Electroencephalogram, pp. 535-553. Ed. by H. Gastaut and J. S. Mayer. Thomas, Springfield, Illinois.

Gauk, E. W., Kidd, L., and Prichard, J. S. (1963). Mechanism of seizures associated with breath-holding spells. New England Journal of Medicine, 268, 1436-1441.

Guilleminault, C., Ariagno, R., Souquet, M., and Dement, W. C. (1976). Abnormal polygraphic findings in near-miss sudden infant death. Lancet, 1, 1326-1327.

Havland, T., and Frithz, G. (1976). A hazard of apple eating. British Medical Journal, 2, 643.

Holowach, J., and Thurston, D. L. (1963). Breath-holding spells and anemia. New England Journal of Medicine, 268, 21-23.

Keeton, B. R., Southall, E., Rutter, N., Anderson, R. H., Shinebourne, E. A., and Southall, D. A. (1977). Cardiac conduction disorders in six infants with "near-miss" sudden infant deaths. British Medical Journal, 2, 600-601.

Keipert, J. A. (1969). Epilepsy precipitated by bathing: water immersion epilepsy. Australian Paediatric Journal, 5, 244-247.

Keipert, J. A. (1972). A new form of sensory precipitation epilepsy: epilepsy precipitated by undressing. Medical Journal of Australia, 2, 1124-1126.

Landman, M. E., and Ehrenfeld, I. (1952). Ventricular fibrillation following eyeball pressure in a case of paroxysmal supraventricular tachycardia. American Heart Journal, 43, 791-795.

Lennox-Buchthal, M. A. (1973). Febrile Convulsions. Elsevier, Amsterdam.

Lennox-Buchthal, M. A. (1976). A summing up: clinical session. Brain Dysfunction in Infantile Febrile Convulsions, pp. 327-351. Ed. by M. A. B. Brazier and F. Coceani. Raven Press, New York.

Levine, S. A. (1915). The oculocardiac reflex. Archives of Internal Medicine, 15, 758-785.

Lombroso, C. T., and Lerman, P. (1967). Breath-holding spells (cyanotic and pallid infantile syncope). Pediatrics, 39, 563-581.

McGreal, D. A. (1956). Observations on febrile convulsions. Americal Journal of Diseases of Children, 92, 504-505.

McGreal, D. A. (1957). Convulsions in childhood. A clinical and electroencephalographic study of 500 cases in children under the age of seven. MD thesis, University of St. Andrews.

Mallinson, F. B., and Coombes, S. K. (1960). A hazard of anaesthesia in ophthalmic surgery. Lancet, 1, 574-575.

Maulsby, R., and Kellaway, P. (1964). Transient hypoxic crises in children. Neurological and Electroencephalo. graphic Correlative Studies in Infancy, pp. 349-360. Ed. by P. Kellaway and I. Petersén. Grune and Stratton New York.

Miller, F. J. W., Court, S. D. M., Walton, W. S., and Knox, E. G. (1960). Growing Up in Newcastle-upon-Tyne, p. 165. Oxford University Press, London.
Mofenson, H. C., Weymuller, C. A., and Greencher, J. (1965). Epilepsy due to water immersion. Journal of the American Medical Association, 191, 600-601.

Parkinson, J., Papp, C., and Evans, W. (1941). The electrocardiogram of the Stokes-Adams attack. British Medical Journal, 3, 171-199.

Pearn, J. H. (1977). Epilepsy and drowning in childhood. British Medical Journal, 1, 1510-1511.

Radford, D. J., Izukawa, T., and Rowe, R. D. (1977). Evaluation of children with ventricular arrythmias. Archives of Disease in Childhood, 52, 345-353.

Robson, P. (1970). Shuffling, hitching, scooting, or sliding: some observations in 30 otherwise normal children. Developmental Medicine and Child Neurology, 12, 608-617.

Robson, P. (1977). Variations of normal motor development. Paper presented at meeting of European Federation of Child Neurology Societies, Braunlage.

Rossen, R., Kabat, H., and Anderson, J. P. (1943). Acute arrest of cerebral circulation in man. Archives of Neurology and Psychiatry, 50, 510-528.

Schwartz, P. J. (1976). Cardiac sympathetic innervation and the sudden infant death syndrome: a possible pathogenetic link. American Journal of Medicine, 60, 167-172.

Schwartz, S. P., and Schwartz, L. S. (1966). The mechanisms of Adams-Stokes seizures. Mechanisms and Therapy of Cardiac Arrhythmias, pp. 477-486. Ed by L. S. Dreifus and W. Likoff. Grune and Stratton, New York.

Scott, O., Macartney, F. J., and Deverall, P. B. (1976). Sick sinus syndrome in children. Archives of Disease in Childhood, 51, 100-105.

Sharpey-Schafer, E. P. (1956). Syncope. British Medical Journal, 1, 506-509.

Sheldon, W. (1952). Syncopal attacks in infancy. Great Ormond Street Journal, 3, 20-22.

Simpson, K. (1949). Deaths from vagal inhibition. Lancet, 1 , 558-560.

Sorensen, E. J., and Gilmore, J. E. (1956). Cardiac arrest during strabismus surgery. American Journal of Ophthalmology, 41, 748-752.

Stephenson, H. E. (1974). Cardiac Arrest and Resuscitation, 4th ed. Mosby, St. Louis; Kimpton, London.

Stokes, W. (1846). Observations on some cases of permanently slow pulse. Dublin Quarterly Journal of Medical Science, 2, 73-85.

Swaiman, K. F., and Wright, F. S. (1975a). The Practice of Pediatric Neurology, Vol. 2, p. 848. Mosby, St. Louis.

Swaiman, K. F., and Wright, F. S. (1975b). The Practice of Pediatric Neurology, Vol. 2, p. 876. Mosby, St. Louis.

Temkin, O. (1971). The Falling Sickness, 2nd ed., p. 341 Johns Hopkins Press, Baltimore.

Weiss, S., and Ferris, E. B. Jr. (1934). Adams-Stokes syndrome with transient complete heart block of vagovagal reflex origin. Archives of Internal Medicine, 54, 931-951.

Correspondence to Dr J. B. P. Stephenson, Fraser of Allander Assessment Unit, Royal Hospital for Sick Children, Glasgow G3 8SJ. 